\title{
Karst Aquifer Water Inflow into Tunnels: An Analytical Solution
}

\author{
Chong Jiang $\mathbb{D}^{1}{ }^{1}$ Haixia Han, ${ }^{1}$ Hansong Xie, ${ }^{1}$ Jing Liu, ${ }^{1}$ Zhao Chen, ${ }^{2}$ and Huawei Chen ${ }^{2}$ \\ ${ }^{1}$ School of Resources and Safety Engineering, Central South University, Changsha, 410083 Hunan, China \\ ${ }^{2}$ Hunan Survey and Design Institute of Communication, 410003, China \\ Correspondence should be addressed to Chong Jiang; jiang4107@sohu.com
}

Received 18 November 2020; Revised 29 December 2020; Accepted 31 December 2020; Published 15 January 2021

Academic Editor: Yanlin Zhao

Copyright (C) 2021 Chong Jiang et al. This is an open access article distributed under the Creative Commons Attribution License, which permits unrestricted use, distribution, and reproduction in any medium, provided the original work is properly cited.

\begin{abstract}
This study gives two new analytical solutions to the tunnel by high-pressure water in the cavern. Firstly, it deals with the analytical solution for the seepage inflow in unsupported karst aquifer tunnels considering the boundary condition. Secondly, it focuses on the study of the seepage force and gives the reduction coefficient of lining water pressure. A comparison of the analytical solution and the finite element software shows a curve relationship as the relevant permeability coefficient $\beta$ increases. The results show that the analytical solution and numerical solution are consistent. As $d$ increases, $\beta$ decreases gradually. $\beta$ increases as $r_{w}$ increases or the grouting circle and initial support become thinner or the secondary lining becomes thicker. In summary, the analytical solution of $\beta$ can be used to predict the seepage inflow and the seepage force of the actual engineering.
\end{abstract}

\section{Introduction}

There are two types of karst aquifer tunnels: sealed and drained [1]. When designing the sealed tunnels, the lining withstands full hydrostatic pressure and earth pressure [2]. However, the seepage inflow and the head pressure of the lining structure need to be taken into account in the design of the tunnels. Therefore, one of the safety issues is to estimate the seepage inflow and the head pressure of the lining structure acting on the lining.

Early researchers have investigated the problems of deep underwater tunnels and given some solutions to these problems, but they have not been applied to actual engineering [3-5]. Some researchers solved the analytical solution for the groundwater inflow based on the theory of hydraulics and image method [6-9]. Park et al. [10] carefully studied the two boundary conditions around the circumference of the underwater tunnel and deduced two analytical solutions for the groundwater inflow into a tunnel. A seepage filed analytical solution for a lined tunnel was derived, but they only considered one layer of linings $[11,12]$. Two types of filled karst caves, with water and with water-mud mixture, in front of the tunnel face are studied to estimate the required thickness of the supporting rock stratum in order to prevent water and mud inrush under earthquake action [13]. Zhang [14],
Zheng [15], Kong [16], Shin et al. [17], and Cao et al. [18] derived the analytical solution of water pressure acting on the lining or rock tunnels. Zhang et al. [19] suggested a new set of analytical solutions for predicting the effect of grouting on ground and shield tunnel behavior as a consequence of steady water inflow into a tunnel in saturated clay based on relative permeability of the tunnel lining and grouting material to the surrounding soil. Huang et al. [20] and Perrochet and Dematters [21] established and calculated numerical models to verify theoretical calculations and predict transient discharge flow into a tunnel drilled at various speeds through a heterogeneous formation. Based on a theoretical method for laminar and turbulent flow, Joo and Shin [22] investigated the relationship between water pressure and inflow rate in underwater tunnels and buried pipes. Li et al. [11]. Based on the image method and theory of seepage mechanics, the analytical solution for the steady seepage field of twinparallel tunnels in the semi-infinite plane was derived and was compared and verified with the numerical solution [23, 24]. A new analytical solution for the karst tunnel was given by Jiang et al. [25] based on mirror image and inversion mapping. Considering the parameters, Xie et al. [26] solved the analytical solution for the karst tunnel based on conformal mapping, but they only considered one of the tunnel boundaries. Park et al. [27] showed the analytical solutions for the 


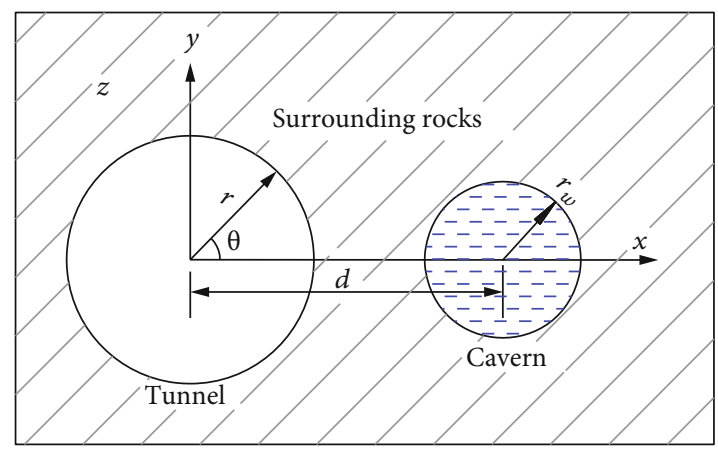

(a)

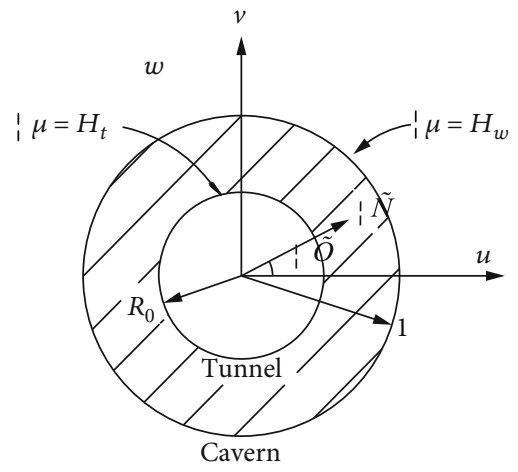

(b)

Figure 1: Theoretical model of the unsupported tunnel. (a) The tunnel and the cavern in the infinite aquifer. (b) Plane of conformal mapping.

seepage force acting on the lining in a drained circular tunnel under the steady-state groundwater flow condition. And some scholars have studied the shear and fracture properties of the surrounding rock [28-31].

Various methods have been developed to estimate the groundwater inflow for deep underwater tunnels. However, there are few analytical solutions for the seepage force of karst aquifer tunnels. This study consists of two parts. First, it deals with the analytical solution for the seepage inflow in the karst aquifer tunnel considering the boundary conditions. And the seepage inflow of unsupported tunnels and supported tunnels is discussed separately. The second part focuses on the study of the karst aquifer tunnel lining structure and gives the analytical solution of the seepage force. And a parameter of the lining water pressure is proposed. The numerical analysis and analytical solution are compared to investigate the effect of different parameters.

\section{Analytical Solution of the Tunnel Seepage Field}

2.1. Assumption. The basic assumptions of this paper are as follows:

(1) The tunnel and the cavern have large depths, and the tunnel is infinitely long, so the working surface is a two-dimensional infinite plane, and the gravity is not considered

(2) The surrounding rock is an isotropic and continuous medium

(3) The seepage of karst water into the tunnel conforms to Darcy's law, and the water pressure in the cavern is equal everywhere

2.2. Conformal Mapping. The center of the tunnel is used as an origin in the Cartesian coordinate system, with the horizontal direction represented by the $x$-axis and the vertical direction represented by the $y$-axis, as shown in Figure 1(a). $r$ and $r_{w}$ are radii of the tunnel and the cavern, respectively. The center distance between the tunnel and the cavern is $d$. The tunnel and the cavern in the $z$-plane are mapped onto two concentric circles of radii $R_{0}$ and 1 , in the $w$-plane by the analytic function (Figure 1(b)) [26].

The analytic function of mapping is

$$
z=\frac{w a-1}{w r-r a}
$$

where $a$ and $R_{0}$ are parameters defined as

$$
a=\frac{d^{2}-r_{w}^{2}-r^{2}-\sqrt{\left(\left(d+r_{w}\right)^{2}-r^{2}\right)\left(\left(d-r_{w}\right)^{2}-r^{2}\right)}}{4 d}
$$

$$
\begin{gathered}
R_{0}=\frac{d^{2}-r_{w}^{2}-r^{2}-\sqrt{\left(\left(d+r_{w}\right)^{2}-r^{2}\right)\left(\left(d-r_{w}\right)^{2}-r^{2}\right)}}{2 r r_{w}} \\
\left(0<R_{0}<1\right),
\end{gathered}
$$

By considering the boundary conditions and the Laplace equation in the $w$-plane, the solution for the total head on a circle with radius $\rho$ can be expressed as

$$
\begin{aligned}
\phi= & C_{1}+C_{2} \ln \rho+\sum_{n=1}^{\infty}\left(C_{3} \rho^{\mathrm{n}}+C_{4} \rho^{-n}\right) \cos n \varphi \\
& +\sum_{n=1}^{\infty}\left(C_{5} \rho^{n}+C_{6} \rho^{-n}\right) \sin n \varphi,
\end{aligned}
$$

where $\phi=P / \gamma_{w}+y, P$ is the water pressure, $\gamma_{w}$ is the unit weight of water, and $y$ is the elevation head. $C_{1}, C_{2}, C_{3}, C_{4}$, $C_{5}$, and $C_{6}$ are constants to be determined from the boundary conditions at the tunnel and the cavern circumference. $n$ is the natural number, and $\varphi$ is the angle between $\rho$ and $u$ -axis in the $w$-plane. 


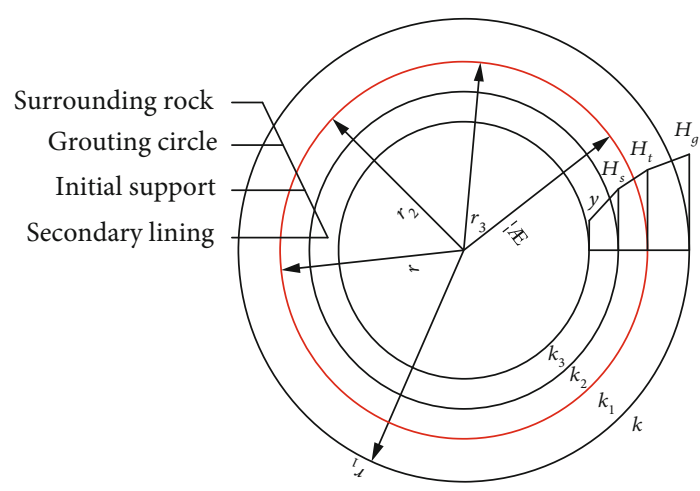

Figure 2: Relationships between lining structures. $H_{t}, H_{s}$, and $y$ are pressure heads along the joints of the grouting circle and initial support circumference, the initial support and secondary lining circumference, and the secondary lining inner circumference, respectively. $r_{1}, r_{2}$, and $r_{3}$ are radii of the grouting circle, initial support, and internal of the secondary lining, respectively. $k_{1}, k_{2}$, and $k_{3}$ are permeability coefficients of the grouting circle, initial support, and secondary lining, respectively.

2.3. The Boundary Condition. The boundary condition of the cavern circumference is $\phi=H_{w}$.

$$
\begin{aligned}
\phi(\rho=1) & =C_{1}+\sum_{n=1}^{\infty}\left(C_{3}+C_{4}\right) \cos n \varphi+\sum_{n=1}^{\infty}\left(C_{5}+C_{6}\right) \sin n \varphi \\
& =H_{w} \longrightarrow C_{1}=H_{w}, \quad C_{3}=-C_{4}, C_{5}=-C_{6} .
\end{aligned}
$$

The boundary condition of the tunnel circumference is $P=0$, so $\phi=y$.

By considering $w=R_{0} \exp (i \varphi)$ in the $w$-plane, the elevation head around the tunnel circumference can be expressed as

$$
y=\sum_{n=1}^{\infty}\left(a^{2}-1\right) a^{n-1} R_{0}^{n} r \sin n \varphi
$$

$$
\begin{aligned}
\phi\left(\rho=R_{0}\right)= & C_{1}+C_{2} \ln \rho+\sum_{n=1}^{\infty} C_{3}\left(R_{0}^{n}+R_{0}^{-n}\right) \cos n \varphi \\
& +\sum_{n=1}^{\infty} C_{5}\left(R_{0}^{n}+R_{0}^{-n}\right) \sin n=y \longrightarrow C_{2} \\
= & -\frac{H_{w}}{\ln R_{0}}, \quad C_{3}=0, C_{5}=\frac{r\left(a^{2}-1\right) a^{n-1} R_{0}^{2 n}}{R_{0}^{2 n}-1},
\end{aligned}
$$

so,

$\phi=H_{w}-\frac{H_{w}}{\ln R_{0}} \ln \rho+\sum_{n=1}^{\infty} \frac{r\left(a^{2}-1\right) a^{n-1} R_{0}^{2 n}}{R_{0}^{2 n}-1}\left(R_{0}^{n}+R_{0}^{-n}\right) \sin n \varphi$.

The seepage per unit length of the tunnel length is

$$
Q=k \int_{0}^{2 \pi} \frac{\partial \phi}{\partial \rho} \rho d \varphi=-\frac{2 \pi k H_{w}}{\ln R_{0}}
$$

where $k$ is the permeability coefficient of the surrounding rock.

\section{The Seepage Force of the Supported Tunnel}

The support of the tunnel includes the grouting circle, initial support, and secondary lining, as shown in Figure 2. It is assumed that the pressure heads of support circumferences are equal and constant. And the seepage inflow through the supports is equal to the tunnel seepage inflow.

For the restricted row tunnel, the excavation of the tunnel has an effect on the seepage field of the surrounding rocks, and the seepage force has also changed. The pressure head of any point within the secondary lining can be obtained, according to Darcy's law and their boundary conditions $\left(\zeta=r_{3}, h=0 ; \zeta=\zeta, h=H_{1 s}\right)$, and $\zeta$ is the radius of any point within the secondary lining in the $w$-plane.

$$
H_{1 s}=\frac{H_{w}}{-\left(k_{3} / k\right) \ln R_{0 s}+\left(k_{3} / k_{1}\right) \ln \left(r_{1} / r\right)+\left(k_{3} / k_{2}\right) \ln \left(r / r_{2}\right)+\ln \left(r_{2} / r_{3}\right)} \ln \frac{\zeta}{r_{3}},
$$

where

$R_{0 s}=\frac{d^{2}-r_{w}^{2}-r_{1}^{2}-\sqrt{\left(\left(d+r_{w}\right)^{2}-r_{1}^{2}\right)\left(\left(d-r_{w}\right)^{2}-r_{1}^{2}\right)}}{2 r_{1} r_{w}}$
The water pressure on the outside of the secondary lining can be derived from Equation (10) when $\zeta=r_{2}$, and it approximated to hydrostatic pressure.

$$
P=\gamma_{w} H_{s}=\frac{\gamma_{w} H_{w}}{-\left(k_{3} / k\right) \ln R_{0 s}+\left(k_{3} / k_{1}\right) \ln \left(r_{1} / r\right)+\left(k_{3} / k_{2}\right) \ln \left(r / r_{2}\right)+\ln \left(r_{2} / r_{3}\right)} \ln \frac{r_{2}}{r_{3}}=\beta \gamma_{w} H_{w},
$$


TABle 1: Characteristic data for verification.

\begin{tabular}{cccccccccc}
\hline$r(\mathrm{~m})$ & $r_{1}(\mathrm{~m})$ & $r_{2}(\mathrm{~m})$ & $r_{3}(\mathrm{~m})$ & $r_{w}(\mathrm{~m})$ & $k\left(\mathrm{~cm} \cdot \mathrm{s}^{-1}\right)$ & $k_{1}\left(\mathrm{~cm} \cdot \mathrm{s}^{-1}\right)$ & $k_{2}\left(\mathrm{~cm} \cdot \mathrm{s}^{-1}\right)$ & $k_{3}\left(\mathrm{~cm} \cdot \mathrm{s}^{-1}\right)$ & $d(\mathrm{~m})$ \\
\hline 6 & 9 & 5.5 & 5 & 5.5 & $10^{-6}$ & $10^{-7}$ & $10^{-8}$ & $10^{-10}$ & 16.5 \\
\hline
\end{tabular}

where $\beta$ is the reduction coefficient of lining water pressure.

$$
\beta=\frac{\ln \left(r_{2} / r_{3}\right)}{-\left(k_{3} / k\right) \ln R_{0 s}+\left(k_{3} / k_{1}\right) \ln \left(r_{1} / r\right)+\left(k_{3} / k_{2}\right) \ln \left(r / r_{2}\right)+\ln \left(r_{2} / r_{3}\right)} .
$$

The unit seepage force at any point in the secondary lining can be expressed as

$$
f=-\gamma_{w} \frac{\partial H_{1 s}}{\partial t}=-\frac{\gamma_{w} H_{w}}{\zeta\left(-\left(k_{3} / k\right) \ln R_{0 s}+\left(k_{3} / k_{1}\right) \ln \left(r_{1} / r\right)+\left(k_{3} / k_{2}\right) \ln \left(r / r_{2}\right)+\ln \left(r_{2} / r_{3}\right)\right)} .
$$

After the integration, the seepage force on the outside of the secondary lining is

$$
F_{s}=\int_{r_{3}}^{r_{2}} f d \zeta=-\frac{\gamma_{w} H_{w}}{-\left(k_{3} / k\right) \ln R_{0 s}+\left(k_{3} / k_{1}\right) \ln \left(r_{1} / r\right)+\left(k_{3} / k_{2}\right) \ln \left(r / r_{2}\right)+\ln \left(r_{2} / r_{3}\right)} \ln \frac{r_{2}}{r_{3}}=-\beta \gamma_{w} H_{w}=-P .
$$

The pressure head on the outside of the initial support can be obtained, according to its boundary conditions.

$$
\begin{aligned}
H_{t}= & \frac{H_{w}}{-\left(k_{3} / k\right) \ln R_{0 s}+\left(k_{3} / k_{1}\right) \ln \left(r_{1} / r\right)+\left(k_{3} / k_{2}\right) \ln \left(r / r_{2}\right)+\ln \left(r_{2} / r_{3}\right)} \ln \frac{r_{2}}{r_{3}} \\
& +\frac{H_{w}}{-\left(k_{2} / k\right) \ln R_{0 s}+\left(k_{2} / k_{1}\right) \ln \left(r_{1} / r\right)+\ln \left(r / r_{2}\right)+\left(k_{2} / k_{3}\right) \ln \left(r_{2} / r_{3}\right)} \ln \frac{r}{r_{2}} .
\end{aligned}
$$

is

And the seepage force on the outside of the initial support

$$
F_{t}=-\frac{\gamma_{w} H_{w}}{-\left(k_{2} / k\right) \ln R_{0 s}+\left(k_{2} / k_{1}\right) \ln \left(r_{1} / r\right)+\ln \left(r / r_{2}\right)+\left(k_{2} / k_{3}\right) \ln \left(r_{2} / r_{3}\right)} \ln \frac{r}{r_{2}} .
$$


The pressure head on the outside of the grouting circle can be obtained, according to its boundary conditions.

$$
\begin{aligned}
H_{g}= & \frac{H_{w}}{-\left(k_{3} / k\right) \ln R_{0 s}+\left(k_{3} / k_{1}\right) \ln \left(r_{1} / r\right)+\left(k_{3} / k_{2}\right) \ln \left(r / r_{2}\right)+\ln \left(r_{2} / r_{3}\right)} \ln \frac{r_{2}}{r_{3}} \\
& +\frac{H_{w}}{-\left(k_{2} / k\right) \ln R_{0 s}+\left(k_{2} / k_{1}\right) \ln \left(r_{1} / r\right)+\ln \left(r / r_{2}\right)+\left(k_{2} / k_{3}\right) \ln \left(r_{2} / r_{3}\right)} \ln \frac{r}{r_{2}} \\
& +\frac{H_{w}}{-\left(k_{1} / k\right) \ln R_{0 s}+\ln \left(r_{1} / r\right)+\left(k_{1} / k_{2}\right) \ln \left(r / r_{2}\right)+\left(k_{1} / k_{3}\right) \ln \left(r_{2} / r_{3}\right)} \ln \frac{r_{1}}{r} .
\end{aligned}
$$

The seepage force on the outside of the grouting circle is

$$
F_{g}=-\frac{\gamma_{w} H_{w}}{-\left(k_{1} / k\right) \ln R_{0 s}+\ln \left(r_{1} / r\right)+\left(k_{1} / k_{2}\right) \ln \left(r / r_{2}\right)+\left(k_{1} / k_{3}\right) \ln \left(r_{2} / r_{3}\right)} \ln \frac{r_{1}}{r} .
$$

The seepage force in the surrounding rock is

$$
F_{r}=-\frac{\gamma_{w} H_{w}}{-\ln R_{0 s}+\left(k / k_{1}\right) \ln \left(r_{1} / r\right)+\left(k / k_{2}\right) \ln \left(r / r_{2}\right)+\left(k / k_{3}\right) \ln \left(r_{2} / r_{3}\right)} \ln \frac{R_{0 s}}{r_{1}} .
$$

Before and after the completion of the secondary lining, the difference in the seepage force of the surrounding rock is

$\Delta F_{r}=\frac{\left(k / k_{3}\right) \gamma_{w} H_{w}}{\left(-\ln R_{0 s}+\left(k / k_{1}\right) \ln \left(r_{1} / r\right)+\left(k / k_{2}\right) \ln \left(r / r_{2}\right)+\left(k / k_{3}\right) \ln \left(r_{2} / r_{3}\right)\right)\left(-\ln R_{0 s}+\left(k / k_{1}\right) \ln \left(r_{1} / r\right)+\left(k / k_{2}\right) \ln \left(r / r_{2}\right)\right)} \ln \frac{\ln R_{0 s}}{r_{1}} \ln \frac{r_{2}}{r_{3}}>0$.

From Equation (21), it can be seen that after the completion of the secondary lining, the seepage force of the surrounding rock increases, which means that the direction of the force exerted by the secondary lining on the surrounding rock is away from the direction of the tunnel center.

Then, the tunnel inflow $Q$ and the seepage force on the outside of the secondary lining $F_{s}$ can be rewritten as

$$
\begin{aligned}
& Q=\beta \frac{2 \pi k_{3} H_{w}}{\ln \left(r_{2} / r_{3}\right)}, \\
& F_{s}=-\beta \gamma_{w} H_{w} .
\end{aligned}
$$

\section{Verification and Discussion}

The seepage inflow and the seepage force are important factors reflecting the safety of tunnels in karst areas. It is very important to verify their correctness. The karst water inflow and seepage force are related to $\beta$ according to Equations (22) and (23). So $\beta$ should be verified first. The characteristic parameter values for verification are shown in Table 1 . The model of $100 \times 100 \mathrm{~m}$ is established with FLAC3D. When $r_{g}=r_{1}-r=3 \mathrm{~m}, r_{s}=r-r_{2}=0.5 \mathrm{~m}, r_{l}=r_{2}-r_{3}=0.5 \mathrm{~m}, d=$ $16.5 \mathrm{~m}$, and $r_{w}=5.5 \mathrm{~m}$, the numerical simulation tunnel model consists of 186240 elements, as shown in Figure 3. The pore water pressure at the four points is as follows: 1 $(36.25,-2,50), 2(41.75,-2,44.5), 3(47.25,-2,50)$, and 4 $(41.75,-2,55.5)$, as shown in Figure 4. 


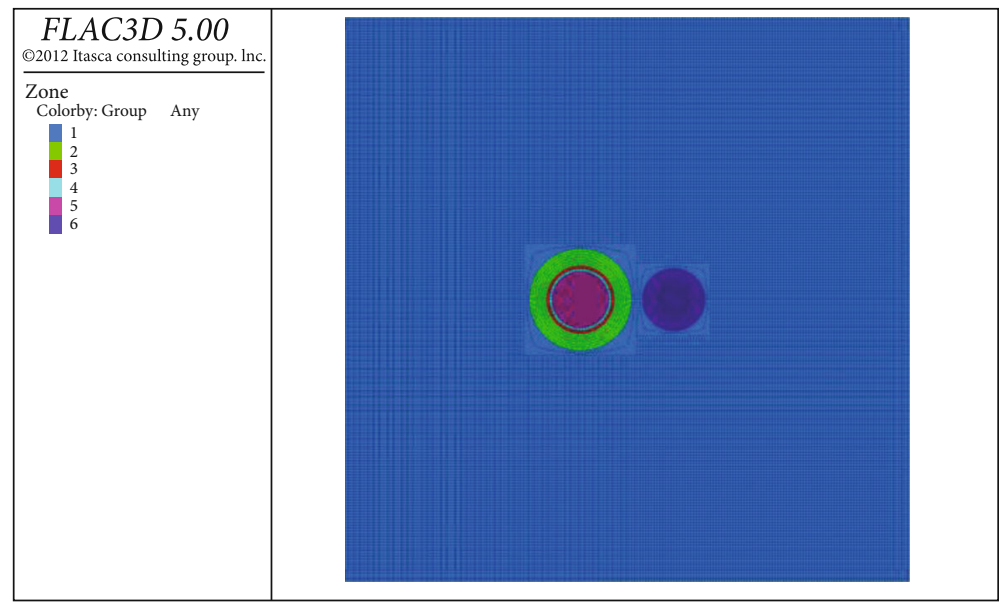

FIGURE 3: The numerical simulation model.

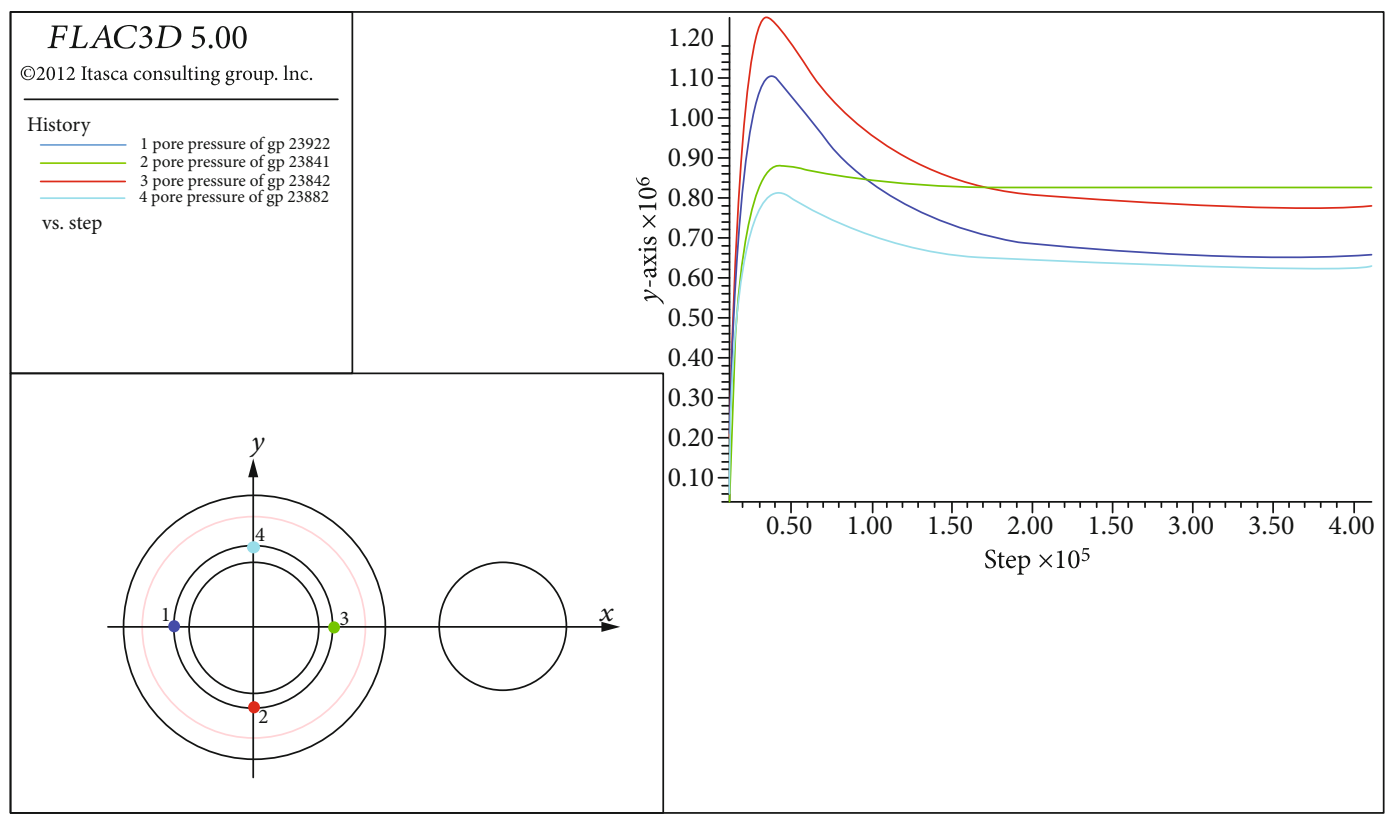

FIGURE 4: Pore water pressure of recorded points.

4.1. The Effect of the Grouting Circle and Surrounding Rock. The influence of the grouting circle and surrounding rock on $\beta$ is described in Figure 5. It can be seen from Figures 5(a) and 5(b) that $\beta$ is increased as the permeability coefficient of the grouting circle increases, regardless of the analytical solution and numerical solution. $\beta$ increases remarkably when $k_{1} / k_{3}<400$. That is to say, $\beta$ can be reduced efficiently by decreasing the permeability of the grouting circle when $k_{1} / k_{3}<400$. In addition, the numerical solution for $\beta$ at point 3 is $97 \%$ of the analytical solution. It can be seen from Figure 5 (a) that when $k_{1}<6.5 \times 10^{-7} \mathrm{~cm}$. $\mathrm{s}^{-1}$, the difference between $\beta$ of different $r_{g}$ decreases gradually. When $k_{1}>6.5 \times 10^{-7} \mathrm{~cm} \cdot \mathrm{s}^{-1}$, the difference between $\beta$ of different $r_{g}$ increases gradually. It shows that the effect of $r_{g}$ on $\beta$ decreases gradually as $k_{1}$ increases. It means that the seepage inflow and pressure head acting on the outside of the secondary lining without grouting are greater than those with grouting, which indicates that grouting can effec- tively control the karst inflow to the tunnel. In summary, the analytical solution and the numerical solution are relatively matched. The smaller the permeability coefficient of the grouting circle, the closer the analytic and numerical simulation solutions will be, and the better the match will be.

Other parameters remained unchanged, and the center distance between the tunnel and the cavern increased from $16.5 \mathrm{~m}$ to $20.5 \mathrm{~m}$. Figure 5(c) shows the relationship between $\beta$ and the center distance. The figure shows that $\beta$ decreases as $d$ increases. In order to make the tunnel lining bear less water pressure, the pressure head, seepage inflow, and seepage force should be smaller; that is, $\beta$ is smaller. Therefore, considering the economic benefits and feasibility study, the tunnel should be designed away from the cavern.

Figure 5(d) illustrates the relationship between $\beta$ and the thickness of the grouting circle. The slope of $\beta$ decreases gradually, and the influence of $r_{g}$ on $\beta$ gradually decreases. $\beta$ tends to be stable when $k_{1}$ gradually approaches $k$. 


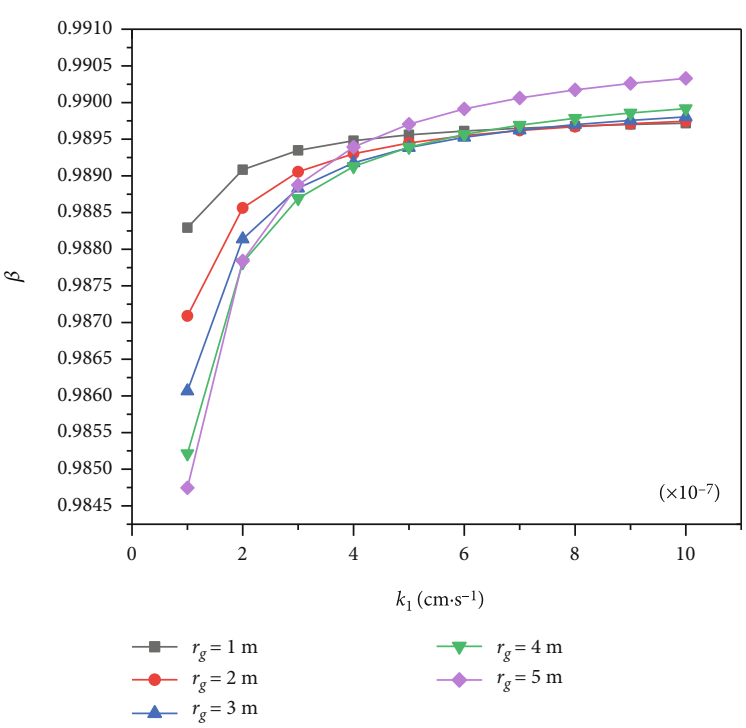

(a)

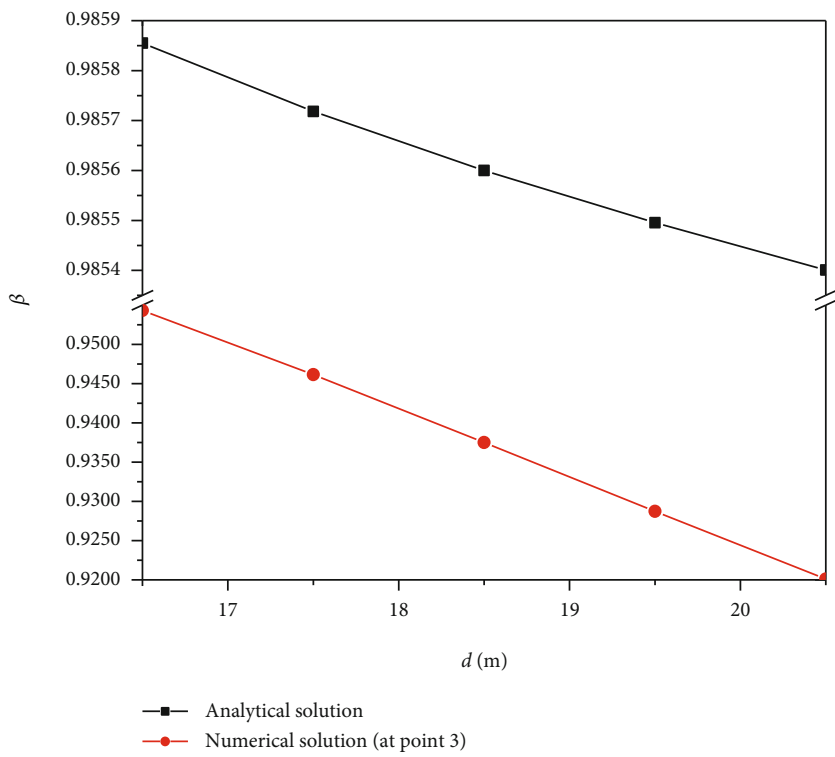

(c)

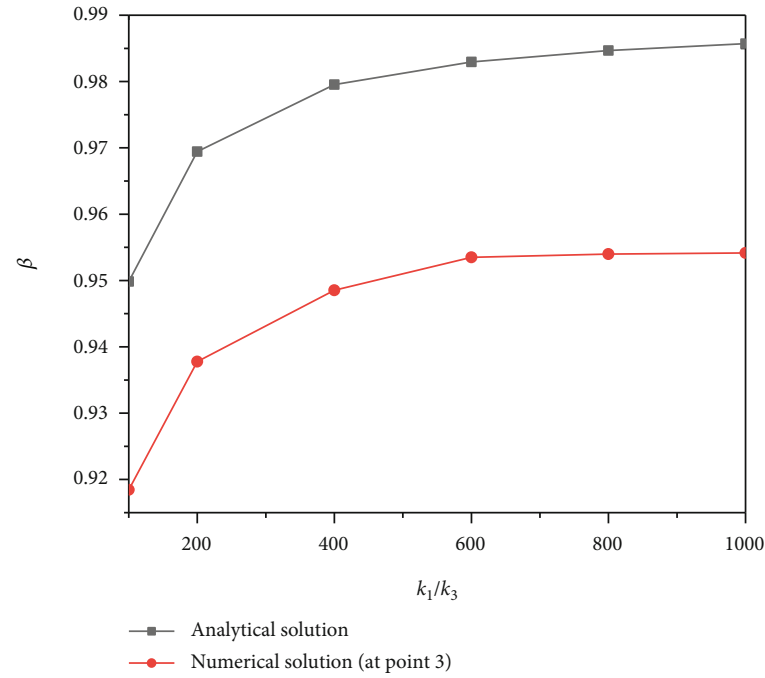

(b)

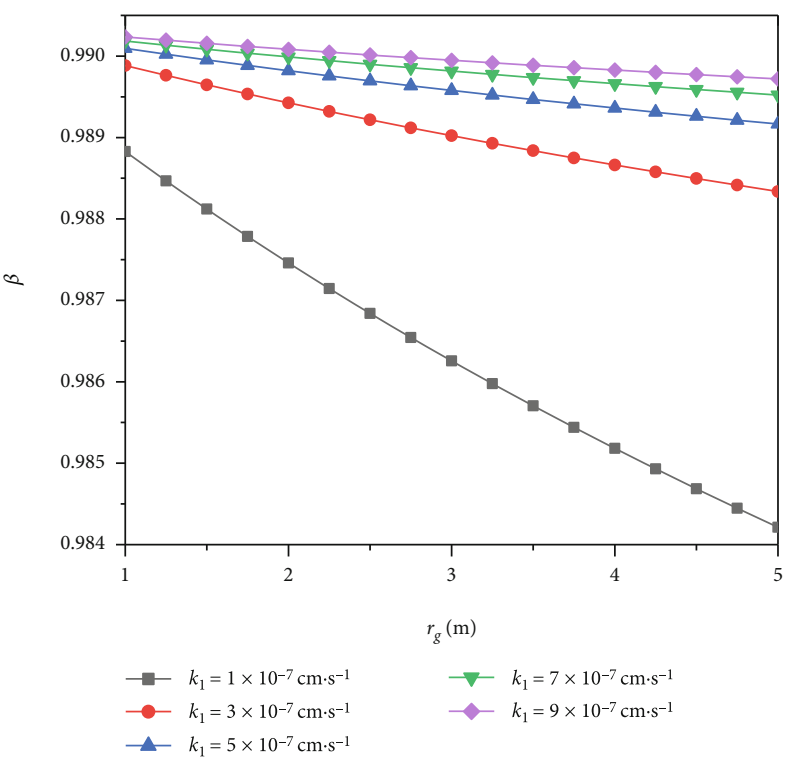

(d)

FIGURE 5: Relationship between $\beta$ and the grouting circle and surrounding rock. (a) Relationship between $\beta$ and $k_{1}$. (b) Comparison of $\beta$ and $k_{1} / k_{3}$. (c) Comparison of $\beta$ and $d$. (d) Relationship between $\beta$ and $r_{g}$.

Therefore, when applying on practical projects, the grouting depth should be appropriately increased during grouting to reduce the water inflow and pressure head acting on the outside of the secondary lining; that is, $\beta$ is smaller. In addition, the simulation results show that $\beta$ decreases linearly with the increase of $r_{g}$, which is consistent with the analytical solution, reflecting that the conformal mapping method in this paper is feasible.

4.2. The Effect of the Initial Support and Secondary Lining. Figures 6(a) and 6(b) illustrate the relationship between $\beta$ and $r_{s}$. It can be seen that the slope of $\beta$ gradually decreases with the increase of $k_{2}$. When $k_{2}<5 \times 10^{-8} \mathrm{~cm} \cdot \mathrm{s}^{-1}$, the change of $\beta$ with $r_{s}$ is obvious. Therefore, in the actual pro- ject, the thickness of the initial support should be increased to reduce the seepage inflow of the tunnel and pressure head on the outside of the secondary lining. When $k_{2}>5 \times 10^{-8}$ $\mathrm{cm} \cdot \mathrm{s}^{-1}, r_{s}$ has little effect on $\beta$, which indicates that the influence of the seepage inflow and pressure head on the outside of the secondary lining is small. Therefore, increasing $r_{s}$ cannot effectively control the inflow of karst water, and it increases the construction cost. And it is not advisable to increase $r_{s}$ indefinitely to resist water pressure.

Figure 6(c) compares $\beta$ between the analytical solution and the simulation solutions, considering the relative permeability of the secondary lining to the initial support. The analytical solution is much larger than the numerical solution for $\beta$ at locations. The analysis is based on an infinite plane, but 


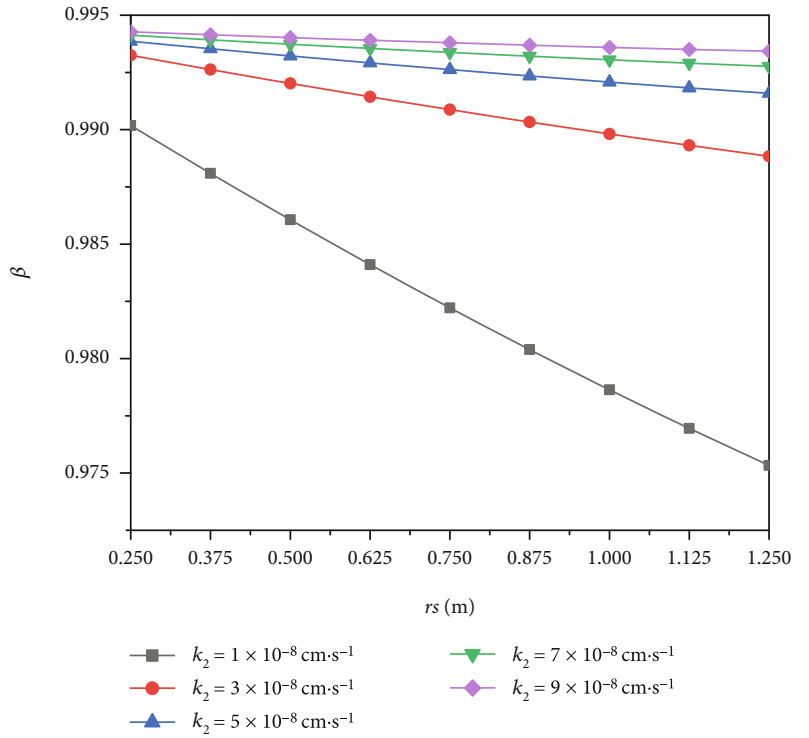

(a)

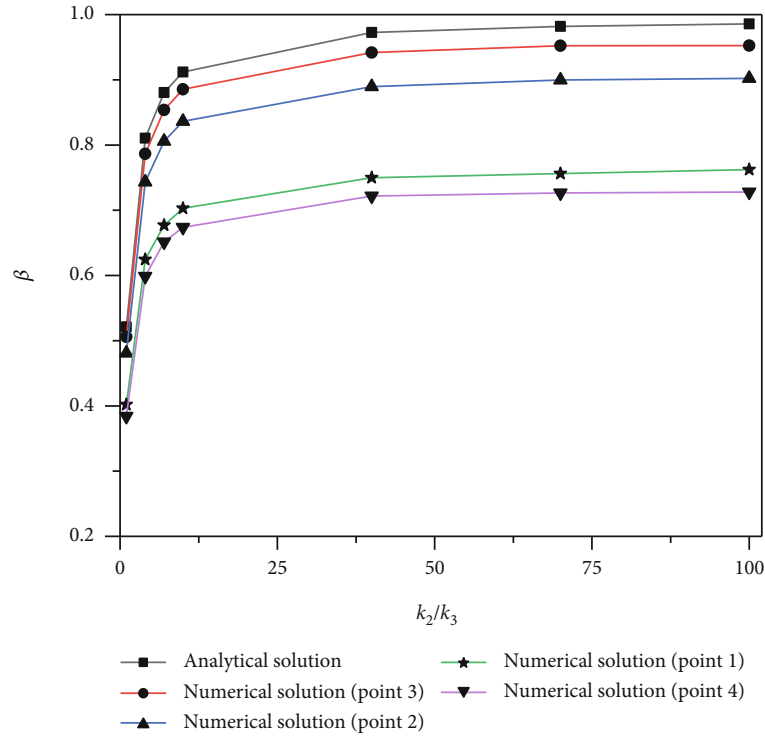

(c)

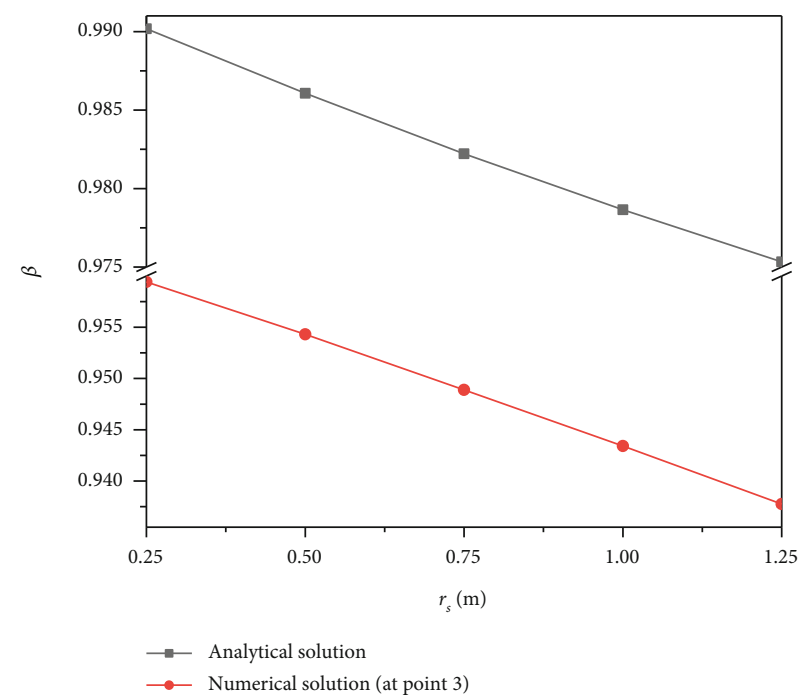

(b)

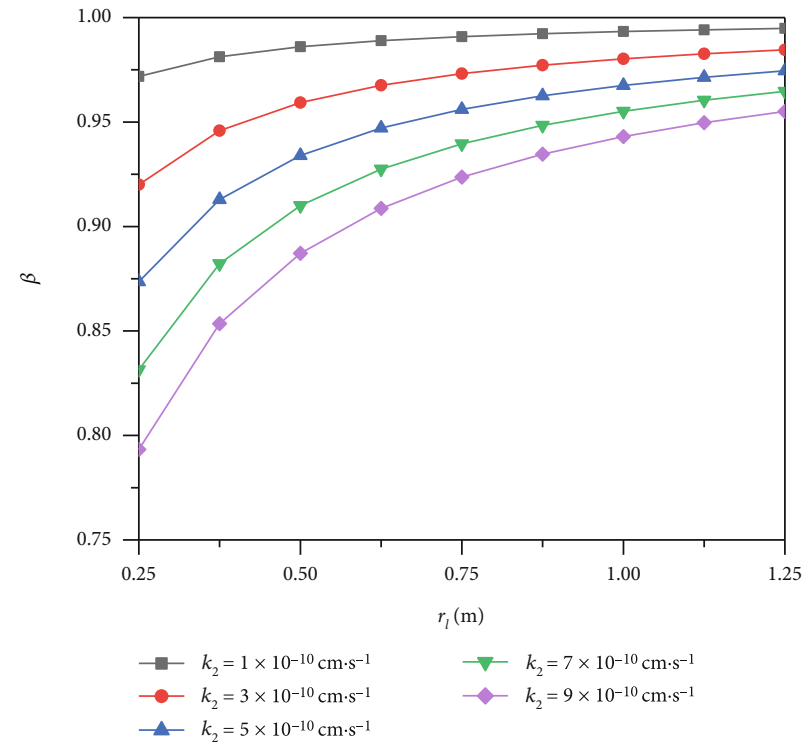

(d)

Figure 6: Relationship between $\beta$ and the initial support. (a) Relationship between $\beta$ and $r_{s}$. (b) Comparison of the numerical solution and theoretical solution. (c) Relationship between $\beta$ and $k_{2} / k_{3}$. (d) Relationship between $\beta$ and $r_{l}$.

the boundaries of numerical simulation are limited. As shown in Figure 6, as the relative permeability increases, the rate of the $\beta$ decrease slows. As the permeability of the initial support decreases, the gap between the analytical and numerical solutions gradually decreases. When the relative permeability is greater than $10, \beta$ gradually stabilizes. In addition, the numerical solution for $\beta$ at point 3 is $97 \%$ of the analytical solution. That is to say, the analytical solution of $\beta$ can be used to predict the seepage inflow and the seepage force of the actual engineering.

The influence of the thickness of the secondary lining $r_{l}$ on $\beta$ is shown in Figure $6(\mathrm{~d})$. When $k_{3}=9 \times 10^{-10} \cdot \mathrm{s}^{-1}, \beta$ reaches stability when $r_{l}=1 \mathrm{~m}$, while when $k_{3}=1 \times 10^{-10}$. $\mathrm{s}^{-1}, \beta$ reaches stability when $r_{l}=0.5 \mathrm{~m}$. It is stated that when $k_{3}$ is a certain value, increasing $r_{l}$ will increase the construction cost and fail to reduce the water inflow and pressure head. Therefore, it is unreasonable to increase the $r_{l}$ infinitely for tunnel seepage safety. Considering the economic benefits and seepage safety of karst aquifer tunnels during construction, $k_{3}$ and $r_{1}$ should be appropriately reduced. Results from the finite difference software show that the increase of $\beta$ with $r_{l}$ tends to be stable at $r_{l}=0.5 \mathrm{~m}$, which is consistent with the analytical solution.

4.3. The Effect of the Cavern. Figure 7 shows the relationship between $\beta$ and $r_{w}$. For various radii of the cave, the reduction coefficients of lining water pressure are almost coincident. The tendencies of the analytical solution and the simulation 


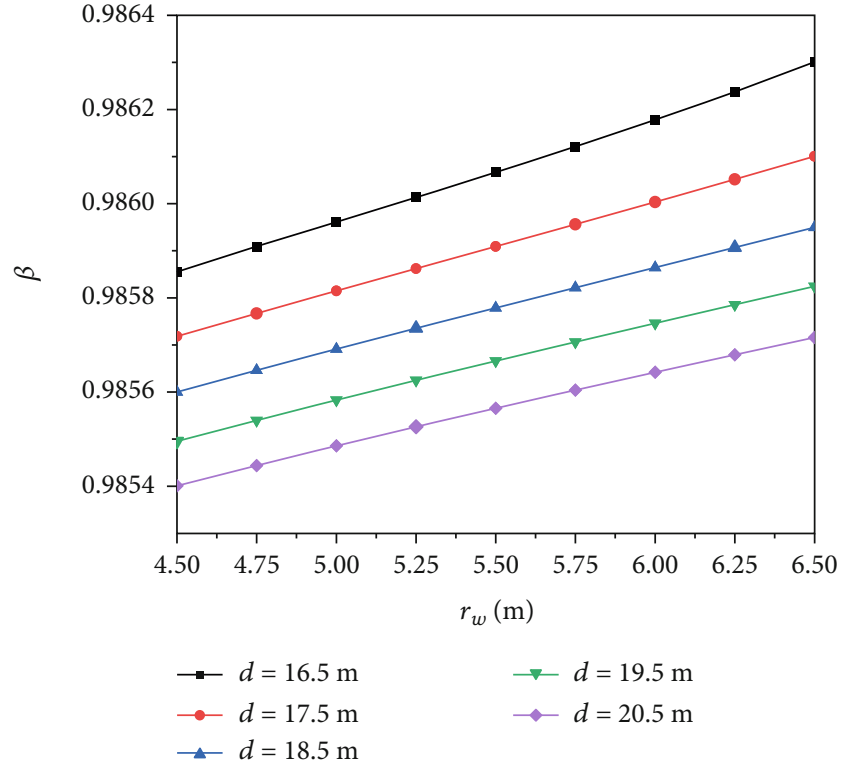

(a)

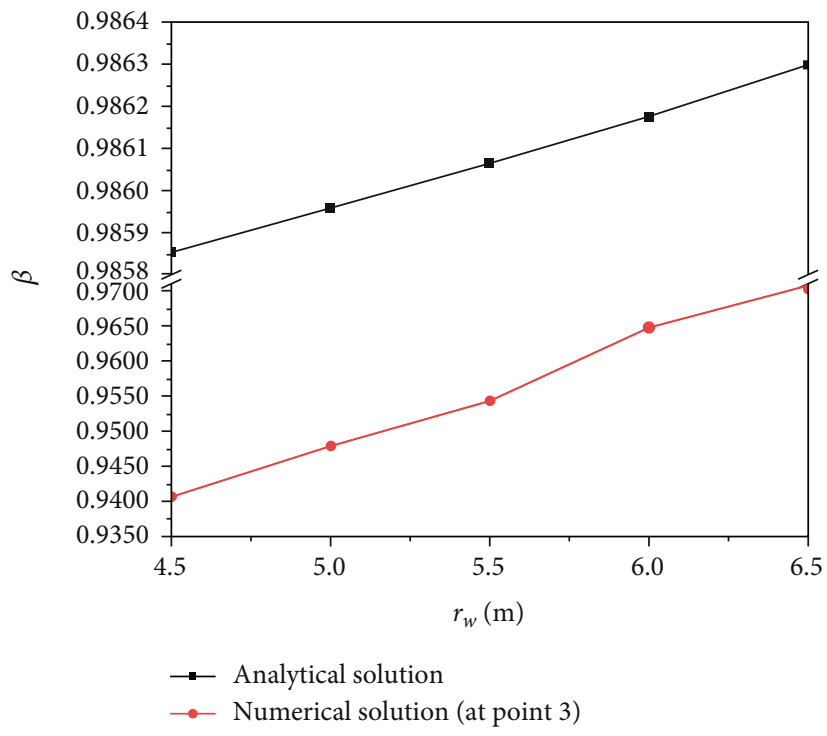

(b)

FIGURE 7: Relationship between $\beta$ and $r_{w}$. (a) Relationship between $\beta$ and $r_{w}$. (b) Comparison of the numerical solution and analytical solution.

solutions are consistent, but they differ in numerical values. The analytical solution is slightly larger than the numerical solution for $\beta$ at point 3 . As shown in Figure 7, $\beta$ increases linearly with the increase of $r_{w}$; in addition, the numerical solution for $\beta$ at point 3 is $95 \%$ of the analytical solution. In summary, the analytical solution of $\beta$ can be used to predict the seepage inflow and the seepage force of the actual engineering.

\section{Conclusion}

This paper derived analytical solutions of the seepage inflow in the unsupported tunnel and lining seepage force in the lined tunnel. The finite element analysis software is used to simulate and calculate the seepage field of the tunnel with lining, and results are compared with analytical solutions to analyze the influencing factors. The conclusions are as follows:

(1) For the seepage problem of tunnels in karst areas, the seepage inflow of unsupported tunnels and supported tunnels can be obtained by complex variable function and seepage mechanics

(2) Assuming that each layer of the lining pressure head is equal, the seepage force of the supported tunnel is solved by seepage mechanics. The analytical solution of the lining water pressure reduction coefficient of the tunnel in the karst area is obtained

(3) The corresponding finite element analysis model is established. The relationship between $\beta$ and the relative permeability of the initial support to the secondary lining, the grouting circle to the secondary lining, and the surrounding rock to the secondary lining is studied from the analytical solution and the numerical solution. And the tendencies of the analytical solution and the simulation solutions are consistent

(4) $\beta$ increases as $k_{2} / k_{3}$ and $k_{1} / k_{3}$ increase. As the permeability of the initial support and grouting circle decreases, the decrease of the analytical solution and numerical solution becomes closer. As $d$ decreases, $\beta$ increases gradually. $\beta$ increases as $r_{w}$ increases or the grouting circle and initial support become thinner or the secondary lining becomes thicker. In summary, the analytical solution of $\beta$ can be used to predict the seepage inflow and the seepage force of the actual engineering

\section{Data Availability}

The data used to support the findings of this study are available from the corresponding author upon request.

\section{Conflicts of Interest}

The authors declare that there are no conflicts of interest regarding the publication of this paper.

\section{Acknowledgments}

This work is supported by the National Natural Science Foundation of China (Grant Nos. 51978665 and 51678570) and Focus on research and development plan of Hunan province (No. 2015SK2053). 


\section{References}

[1] G. Fernández and T. A. Alvarez Jr., "Seepage-induced effective stresses and water pressures around pressure tunnels," Journal of Geotechnical Engineering, vol. 120, no. 1, pp. 108-128, 1994.

[2] A. Bobet, "Effect of pore water pressure on tunnel support during static and seismic loading," Tunnelling and Underground Space Technology, vol. 18, no. 4, pp. 377-393, 2003.

[3] T. Chisyaki, "A study on confined flow of ground water through a tunnel," Ground Water, vol. 22, no. 2, pp. 162$167,1984$.

[4] A. Verruijt, "Complex variable solutions of elastic tunneling problems," Rapport COB 96-04, 1996.

[5] A. Verruijt and J. R. Booker, "Complex variable analysis of Mindlin's tunnel problem," in Development of Theoretical Geomechanics, pp. 3-22, Balkema, Sydney, 2000.

[6] C. Butscher, "Steady-state groundwater inflow into a circular tunnel," Tunnelling and Underground Space Technology, vol. 32, pp. 158-167, 2012.

[7] C. W. Du, M. S. Wang, and Z. S. Tan, "Analytic solution for seepage field of subsea tunnel and its application," Chinese Journal of Rock Mechanics and Engineering, vol. S2, pp. 3567-3573, 2011.

[8] M. El Tani, "Circular tunnel in a semi-infinite aquifer," Tunnelling and Underground Space Technology, vol. 18, no. 1, pp. 49-55, 2003.

[9] H. Zhu, J. Shen, F. Zhang et al., "DEM-CFD modeling of proppant pillar deformation and stability during the fracturing fluid flowback," Geofluids, vol. 2018, Article ID 3535817, 18 pages, 2018.

[10] K. H. Park, J. G. Lee, and A. Owatsiriwong, "Seepage force in a drained circular tunnel: an analytical approach," Canadian Geotechnical Journal, vol. 45, no. 3, pp. 432-436, 2008.

[11] P. Li, F. Wang, Y. Long, and X. Zhao, "Investigation of steady water inflow into a subsea grouted tunnel," Tunnelling and Underground Space Technology, vol. 80, pp. 92-102, 2018.

[12] H. W. Ying, C. W. Zhu, H. W. Shen, and X. N. Gong, "Semianalytical solution for groundwater ingress into lined tunnel," Tunnelling and Underground Space Technology, vol. 76, pp. 43-47, 2018.

[13] J. Wu, S. C. Li, Z. H. Xu, and J. Zhao, "Determination of required rock thickness to resist water and mud inrush from karst caves under earthquake action," Tunnelling and Underground Space Technology, vol. 85, pp. 43-55, 2019.

[14] M. D. Zhang, "Study on the characteristics of seepage field and water pressure on tunnel lining in karst ground," Beijing Jiaotong University, 2008.

[15] B. Zheng, "Practical calculation of water pressure load on tunnel lining," China Academy of Railway Sciences, 2010.

[16] W. K. Kong, "Water ingress assessment for rock tunnels: a tool for risk planning," Rock Mechanics and Rock Engineering, vol. 44, no. 6, pp. 755-765, 2011.

[17] Y. J. Shin, K. I. Song, I. M. Lee, and G. C. Cho, "Interaction between tunnel supports and ground convergence-consideration of seepage forces," International Journal of Rock Mechanics \& Mining Sciences, vol. 48, no. 3, pp. 394-405, 2011.

[18] Y. Cao, J. Jiang, K. H. Xie, and W. M. Huang, "Analytical solutions for nonlinear consolidation of soft soil around a shield tunnel with idealized sealing linings," Computers and Geotechnics, vol. 61, pp. 144-152, 2014.
[19] D. M. Zhang, Z. K. Huang, Z. Y. Yin, L. Z. Ran, and H. W. Huang, "Predicting the grouting effect on leakage-induced tunnels and ground response in saturated soils," Tunnelling and Underground Space Technology, vol. 65, pp. 76-90, 2017.

[20] F. M. Huang, Z. S. Tan, M. S. Wang, and X. Y. Wang, "Analytical solution for water inflow into an underwater tunnel and its application," Engineering Sciences, vol. 11, no. 7, pp. 568-573, 2009.

[21] P. Perrochet and A. Dematters, "Modeling transient discharge into a tunnel drilled in a heterogeneous formation," Ground Water., vol. 52, no. 4, pp. 597-605, 2014.

[22] E. J. Joo and J. H. Shin, "Relationship between water pressure and inflow rate in underwater tunnels and buried pipes," Géotechnique, vol. 64, no. 3, pp. 226-231, 2014.

[23] P. Arjnoi, J. H. Jeong, C. Y. Kim, and K. H. Park, "Effect of drainage conditions on porewater pressure distributions and lining stresses in drained tunnels," Tunnelling and Underground Space Technology., vol. 24, no. 4, pp. 376-389, 2009.

[24] B. Q. Zhang, "Analytical solution for seepage field of twinparallel tunnel in semi-infinite plane," Journal of the China Railway Society, vol. 39, no. 1, pp. 125-131, 2017.

[25] C. Jiang, H. S. Xie, J. L. He, W. Y. Wu, and Z. C. Zhang, "Analytical solution of seepage field in karst tunnel," Advances in Civil Engineering, vol. 2018, Article ID 9215472, 9 pages, 2018.

[26] H. S. Xie, C. Jiang, J. L. He, and H. X. Han, “Analytical solution for the steady-state karst water inflow into a tunnel," Geofluids, vol. 2019, Article ID 1756856, 9 pages, 2019.

[27] K. H. Park, A. Owatsiriwong, and J. G. Lee, "Analytical solution for steady-state groundwater inflow into a drained circular tunnel in a semi-infinite aquifer: a revisit," Tunnelling and Underground Space Technology, vol. 23, no. 2, pp. 206209, 2008.

[28] Y. L. Zhao, C. S. Zhang, Y. X. Wang, and H. Lin, "Shear-related roughness classification and strength model of natural rock joint based on fuzzy comprehensive evaluation," International Journal of Rock Mechanics and Mining Sciences, vol. 13, no. article 104550, 2020.

[29] Y. Zhao, L. Zhang, W. Wang, Q. Liu, L. Tang, and G. Cheng, "Experimental study on shear behavior and a revised shear strength model for infilled rock joints," International Journal of Geomechanics, vol. 20, article 04020141, no. 9, 2020.

[30] Y. Zhao, Y. Wang, W. Wang, L. Tang, Q. Liu, and G. Cheng, "Modeling of rheological fracture behavior of rock cracks subjected to hydraulic pressure and far field stresses," Theoretical and Applied Fracture Mechanics., vol. 101, pp. 59-66, 2019.

[31] Y. L. Zhao, L. Zhang, J. Liao, W. Wang, Q. Liu, and L. Tang, "Experimental study of fracture toughness and subcritical crack growth of three rocks under different environments," International Journal of Geomechanics, vol. 20, no. 8, article 04020128, 2020. 